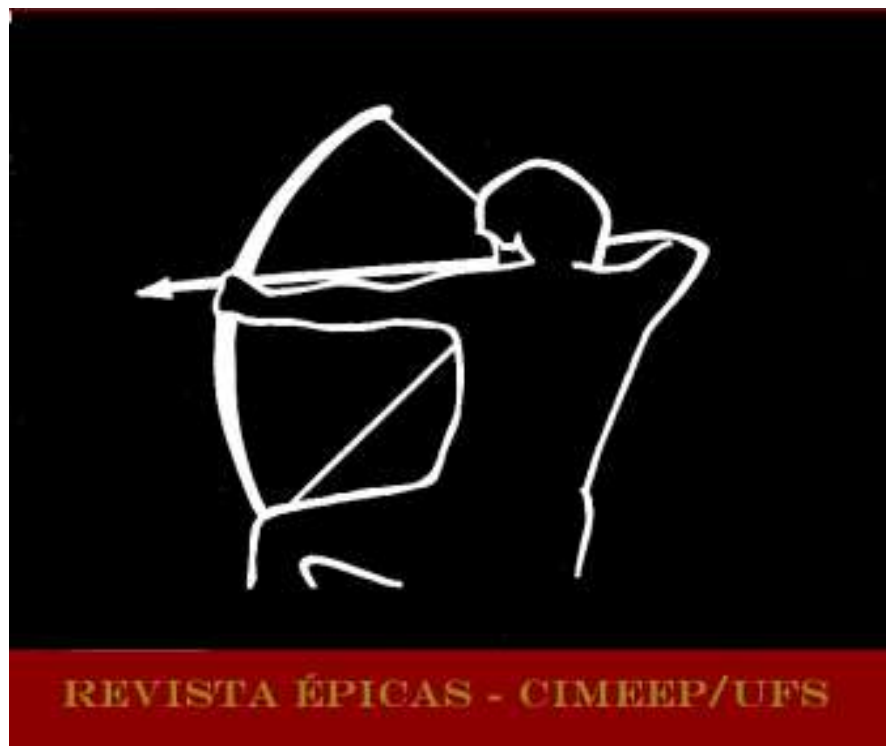

EPIFÂNIO, Renato. O quixotismo metafísico de Leonardo Coimbra e Teixeira de Pascoaes. In: Revista Épicas. Ano 4, N. 7, Jun 2020, p. 1-6. ISSN 2527-080-X.

\title{
O QUIXOTISMO METAFÍSICO DE LEONARDO COIMBRA E TEIXEIRA DE PASCOAES
}

\section{THE METAPHYSICAL QUIXOTICISM OF LEONARDO COIMBRA AND TEIXEIRA DE PASCOAES}

\author{
Renato Epifânio
}

Instituto de Filosofia da Universidade do Porto

RESUMO: Para Leonardo Coimbra, como aqui veremos, o ser humano é qualificado como um "Quixote do Infinito", um "Quixote" que, contudo, à partida "se ignora". Ignorando-se, não pode cumprir ele a sua destinação: dar sentido ao próprio Universo. Para todo aquele que se assume como "Quixote do Infinito", eis, com efeito, do que se trata: de protestar por esse sentido, de exigir essa "resposta do Ser à nossa atitude quixotesca dentro da vida". Mais ainda, trata-se, em última instância, como diria Teixeira de Pascoaes, de exigir que "Deus" passe a existir. Esse é, nas suas palavras, o real fito do "crente verdadeiro". Palavras-chave: Leonardo Coimbra, Teixeira de Pascoaes, Quixotismo, Metafísica.

ABSTRACT: For Leonardo Coimbra, as we will see here, the human being is qualified as a "Quixote of Infinit", a "Quixote" that, however, at the outset "is ignored". Ignoring himself, he cannot fulfill his destiny: giving meaning to the Universe itself. For everyone who assumes himself as "Quixote of Infinit", here is, in effect, what it is about: to protest for that meaning, to demand this "response of the Being to our quixotic attitude in life". Furthermore, it is ultimately a matter, as Teixeira de Pascoaes would say, of demanding that "God" come into being. This, in his words, is the real goal of the "true believer".

Keywords: Leonardo Coimbra, Teixeira de Pascoaes, Quixotism, Metaphysics. 
Na sua obra A Alegria, a Dor e a Graça, Leonardo Coimbra reconhece que "o primeiro aspecto do Ser é incompatível com um Deus criador todo-poderoso e omnisciente" (COIMBRA, 1983, p. 467). Reconhecendo isso - mais do que isso: que "o mal existe como facto" -, a verdade é que Leonardo logo de seguida se interroga, interrogando-nos ao mesmo tempo: “...mas terá ele realidade bastante a determinar um sistema de mundos? Não estará o mal exactamente na escravidão com que o olhamos, na falta de interpretação capaz de o explicar?" (COIMBRA, 1983, p. 469).

A resposta, se pode haver resposta, está, como sempre, como quase sempre, contida na própria interrogação. Se, por um lado, "o mal existe como facto", por outro, ele existe como um facto porque não há argumentos. Leonardo, aliás, é o primeiro a assumi-lo. Daí o falar-nos do "mais inabordável aspecto do mal", que nem sequer, como defende, a hipótese da "queda divina" - defendida, por exemplo, por Sampaio Bruno na sua $A$ Ideia de Deus - pode explicar. E isto porque, no seu entender, essa "queda" ou "diminuição" só poderia advir de "um acto de querer" do próprio "Deus", o que seria absurdo; na hipótese contrária, "regressaríamos, pelo menos, a um dualismo divino" (COIMBRA, 1983, p. 470).

Excluídas todas as hipóteses de explicação, resta-lhe pois apenas, in extremis, a saída da "fé" ou, como prefere dizer, da "aposta": "Teremos, então, uma realidade em que o mal é aparente e encontra justificativa explicação numa mais profunda apreensão da realidade." (COIMBRA, 1983, p. 470). Eis a "saída" que Leonardo Coimbra nos irá reiterar já na terceira e última parte desta sua obra ao formular a seguinte interrogação: "Por que não havemos, pois, de pensar que a nossa visão primitiva é má e que o universo, contendo os nossos valores, é mais que nós, e um grande sentido oculto deve possuir?" (COIMBRA, 1983, p. 517).

Ao contrário do que alguns poderão considerar, não deriva esta "saída" de uma desistência, de uma resignação. Deriva antes, como dissemos, de uma "aposta", que Leonardo Coimbra de forma expressa enuncia: “'ll faut parier...' por Deus ou contra Deus, pelo significado ou pela insensatez do mundo." (COIMBRA, 1983, p. 491). Como Leonardo logo de seguida nos acrescenta, esse é, aliás, um desafio que o próprio "Deus" nos dirige: "A tremenda disjunção, que Pascal põe diante do homem planetário, é, com efeito, a mais profunda, bela e dolorosa manifestação da tragédia da consciência. Parece que, ao erguer-se das profundidades da alma o formidável dilema, o Invisível nos dirige, 
de frente, uma brusca e terrível intimação: Homem decide-te; é a ti, ao teu obstinado proselitismo, que, porventura, cumpre dar valor ao Universo." (COIMBRA, 1983, p. 491).

Eis, efectivamente, do que aqui se trata: não de esperar por uma qualquer revelação divina que enfim nos desocultasse esse "grande sentido que o universo deve possuir", mas de desocultarmos, nós próprios, esse "sentido", esse "grande sentido", assim cumprindo essa "mais profunda apreensão da realidade". Não se trata pois aqui, nessa medida, de uma atitude de desistência, de resignação, mas, ao invés, de uma atitude voluntariosa, temerária, tão temerária que Leonardo chega a qualificá-la como "heróica", como "quixotescamente heróica". Para Leonardo, o homem não é, aliás, senão isso: um "Quixote", um "Quixote do Infinito" (COIMBRA, 1983, p. 485). Um "Quixote" que, contudo, como de forma expressa ressalva Leonardo, à partida "se ignora" (COIMBRA, 1983, p. 486).

Ignorando-se, não pode cumprir ele - o humano - a sua destinação: dar sentido ao próprio Universo, desde logo, como escreveu o seu discípulo José Marinho, à "nossa forma de ser passageira" (MARINHO, 1994, 247). Para todo aquele que se assume como "Quixote do Infinito", eis, com efeito, segundo o próprio Leonardo Coimbra, do que se trata: de protestar por esse sentido, de exigir essa "resposta do Ser à nossa atitude quixotesca dentro da vida" (COIMBRA, 1983, p. 489). Mais ainda, trata-se, em última instância, como diria Teixeira de Pascoaes, de exigir que "Deus" passe a existir. Esse é, aliás, nas palavras do poeta-filósofo, o real fito do "crente verdadeiro": ele não crê em "Deus" porque ele exista - dado que, "se ele existisse, a nossa crença seria inútil ou estéril" (PASCOAES, 1985, p. 320) -, mas, precisamente, "como protesto contra a sua não existência" (PASCOAES, 1985, p. 320), na quixotesca premissa de que "se a nossa crença fosse absoluta, Deus existiria absolutamente" (PASCOAES, 1975, p. 17). Eis, em suma, porque falamos aqui de um "quixotismo metafísico".

Dirão os Sanchos Pança deste mundo que isso é, de todo, "impossível", dado que, se "Deus" não existe, de nada vale acreditarmos nele, pois que não é por nele acreditarmos absolutamente que ele passa a existir. Têm razão. Mas a questão não é essa. A questão é que, como escreveu Antero de Quental, "Deus", "por isso que não é real, é que é verdadeiro" (QUENTAL, 1989, p. 17). De resto, se Pascoaes considera que o "crente verdadeiro" é aquele que exige que "Deus" exista, tal não decorre de nenhum interesse. 0 "Deus" de Pascoaes não existe para nos salvar, nem sequer para atender ao 
nosso "drama da existência". Ele é, literalmente, um "Deus" que não serve para nada. Mas isso só reforça o valor dessa crença, desse louvor. Para incredulidade de todos os Sanchos Pança deste mundo, é precisamente porque "Deus" não serve para nada, que o devemos louvar. Só com esta atitude podemos, de resto, aceder a ele.

Tal como os nautas só descobriram a "Ilha do Amores" quando já não a procuravam, quando já nada procuravam, assim também nós, segundo Leonardo, só encontraremos "Deus" quando já não o procurarmos, quando já nada procurarmos, quando já não tivermos o menor motivo para o encontrarmos. Não chegaremos pois a ele guiados pelos ventos da aflição. Só chegaremos a ele quando nenhum consolo, nenhuma salvação, procurarmos já, quando todos os ventos deixarem enfim de soprar... Não significa isto, contudo, o "repouso", a "dissolução da alma", o mergulho nesse “imenso oceano calmo e silencioso" que o autor d' A Alegria, a Dor e a Graça identifica - não discutiremos aqui se de forma adequada - com o Nirvana (COIMBRA, 1983, p. 475). De modo algum. Nem sequer, aliás, a dissolução da consciência. Muito pelo contrário - ainda nas palavras de Leonardo: “A consciência é, assim, a flor cujas raízes penetram todo o Cosmos, erguendo-o e reintegrando-o no perfume da meditação. Eis porque um Nirvana não responde à ansiedade com que procuramos o lugar das almas." (COIMBRA, 1983, p. 479).

Daí, de resto, a importância, acrescida, da Dor: "A Dor leva ao maior conhecimento, porque obriga a uma indagação em todas as direcções e sem repouso (...)." (COIMBRA, 1983, p. 494). Ao contrário da Alegria, que "banaliza e adormece", a Dor "inquieta e dinamiza" (COIMBRA, 1983, p. 495) - não fosse ela, como escreveu ainda, uma "incessante pergunta" (COIMBRA, 1983, p. 494). Se não houvesse Dor, se não houvesse Cisão, não haveria, de facto, a "incessante pergunta", a própria “interrogação fundamental". Eis, aliás, o que Leonardo salientou-daí o ter-nos dito que “o conhecimento separa os espectadores do Espectáculo" (COIMBRA, 1983, p. 413), daí o ter chegado a escrever que "há qualquer coisa de terrível no conhecimento, e muita profundidade na ideia que o alia com a morte" (COIMBRA, 1983, p. 414). O que a cria é, contudo, aqui o mesmo que a anula - daí Leonardo falar-nos também do "enigma do conhecimento" (COIMBRA, 1983, p. 413). Leonardo poderia, de resto, falar-nos do "enigma da Dor". E isto porque a Dor que é expressão da Cisão relativamente a "Deus" 
é a mesma que a ele, enfim, nos (re)ligará. Precisamente por isso, aliás, fala-nos Leonardo da "função religiosa da dor" (COIMBRA, 1983, p. 574).

Daí o ter-nos dito ainda que "a Dor é o caminho da redenção" (COIMBRA, 1983, p. 595), "o melhor caminho para Deus" (COIMBRA, 1983, p. 498), dado que só ela, alegadamente, "leva os olhos ao fundo do abismo e arranca a profundidade à luz da superfície" (COIMBRA, 1983, p. 496). E por isso caracteriza ainda Leonardo a Dor como uma "grande experiência" (COIMBRA, 1983, p. 497), como uma "cósmica experiência insubstituível" (COIMBRA, 1983, p. 498), ao mesmo tempo que nos assegura que é "para além dos areais da Dor" que podemos encontrar "Deus" (COIMBRA, 1983, p. 496). É ainda, aliás, por isso, precisamente, que Leonardo tanto valoriza o cristianismo - por este ser, nas suas palavras, "a grande religião da dor" (COIMBRA, 1983, p. 495). Todo o cristianismo é, de resto, ainda nas suas palavras, um "ensinamento da Dor" (COIMBRA, 1983,p. 497) - não tivesse sido Jesus aquele que "sondou a Dor até àquele ponto onde ela se transfigura em imortal Alegria" (COIMBRA, 1983, p. 496). Daí, enfim, toda a sua diferença relativamente ao paganismo - ainda nas palavras do autor d' A Alegria, a Dor e a Graça: "Se o paganismo vibra de infantil Alegria naturalista, o cristianismo é a Alegria reconquistada, o sol depois da tempestade, a dignidade e certeza da vida, de olhos abertos e atentos na face da morte." (COIMBRA, 1983, p. 495). Eis, segundo Leonardo, a subtil, a abissal diferença que Nietzsche não terá apreendido.

Daí, de resto, a razão maior pela qual, tendo sido Leonardo um "conhecedor profundo das coordenadas do pensamento de Nietzsche", dele se afastou - como escreveu Américo Enes Monteiro a este respeito: “Aos poucos Leonardo Coimbra vai-se afastando cada vez mais de Nietzsche na sua interpretação do Cristianismo, visto por este como religião da dor que inferioriza, versus Paganismo, a religião da alegria e consequentemente da superioridade. Leonardo, embora admitindo ser o Cristianismo a religião da dor, não considera esta como inferiorizante (...)." (MONTEIRO, 2000, pp. 138 e 144).

\section{Referências bibliográficas}

COIMBRA, Leonardo. Obras de Leonardo Coimbra, vol. I, coordenação e revisão de Sant'Anna Dionísio, Porto, Lello, 1983. 
MARINHO, José. Aforismos sobre o que mais importa, “Obras de José Marinho", vol. I, Lisboa, Imprensa Nacional - Casa da Moeda, 1994.

MONTEIRO, Américo Enes. Recepção da Obra de Friedrich Nietzsche na Vida Intelectual Portuguesa (1892-1939), Porto, Lello, 2000.

PASCOAES, Teixeira de. O Empecido, “Obras Completas", XI, introd. e aparato crítico por Jacinto do Prado Coelho, Lisboa, Livraria Bertrand, 1975.

PASCOAES, Teixeira de. Napoleão, introd. de Fernando Guimarães, Lisboa, Assírio \& Alvim, 1985.

QUENTAL, Antero de. Tendências Gerais da Filosofia na segunda metade do século XIX, org., apres. e notas de Leonel Ribeiro dos Santos, Lisboa, Comunicação, 1989. 